\title{
Development of a Methodology for Analysis of Instability in Room and Pillar Mines
}

\author{
M. Board Itasca Consulting Group, USA \\ B. Damjanac Itasca Consulting Group, USA
}

M. Pierce Itasca Consulting Group, USA

\begin{abstract}
Since 1994, a number of major roof falls and panel collapses have occurred in room and pillar trona mines within the Green River Basin of Wyoming, USA. Trona is a relatively strong and brittle evaporite mineral that occurs in a flat-lying, $3 \mathrm{~m}$ (approximate) thick bed at about $490 \mathrm{~m}$ depth. The floor of the seam is composed of thinly-bedded, weak shale and the roof materials of interbedded shales, marlstones, mudstones and sandstones. The largest of these events, a 5.2 Richter magnitude event, occurred at the Solvay Mine in February, 1995. This event, induced by the collapse of the $1 \mathrm{SW}$ panel (over $2 \mathrm{~km}^{2}$ area), occurred in roughly 5 seconds with a simultaneous surface subsidence of approximately $1 \mathrm{~m}$.

This paper describes a methodology for estimating the potential for major panel collapses developed through back-analysis of several collapse incidents. The method is similar to the "ground reaction curve" approach for ground support design, and involves separate analysis of the stress-strain response of the primary mechanical components of the system: a) the pillar/floor system for a particular pillar design and extraction ratio, and, $b$ ) the overlying roof strata for given panel widths and barrier pillar dimensions. The stress-strain response of the pillar/floor system for a given panel geometry is estimated through backanalysis of instrumented case studies and observations of pillar/floor punching. The stiffness and yield response of the overburden is estimated numerically by replacing the panel pillars with an equivalent backpressure, and then incrementally removing the pressure to allow closure of the seam. The pressuredisplacement response of the two components are superimposed to determine whether an equilibrium state can be achieved, and to estimate the potential violence of the failure response if equilibrium cannot be achieved. Back-analysis of the collapse of three panels at one mine is shown. The method allows rapid analysis of the impacts of adjusting panel extraction ratio, panel span and inter-panel barrier pillar dimensions on global stability, and thus provides a reasonably-simple design analysis tool.
\end{abstract}

\section{Introduction}

A number of large trona (soda ash) mines are located in the Green River Basin, approximately $40 \mathrm{~km}$ west of Green River, Wyoming, US (Figure 1). The mines employ a typical room and pillar mining method utilising continuous and bore miners to extract a $3 \mathrm{~m}$ seam of trona at a depth of approximately $490 \mathrm{~m}$ below ground surface. Longwall mining is also employed at the FMC mine and has recently been initiated at the Solvay mine.

Although the panel layouts vary significantly from mine to mine, typical room and pillar panels are developed by advancing three or more parallel entries (4.6 m + in width) in the centre of the panel, and driven its entire length (about $600 \mathrm{~m}$ ), followed by retreat development of perpendicular panel drifts from the entries to the boundaries of the panel (Figure 2). The extraction on retreat defines a series of $15 \mathrm{~m}$ square chain pillars between entries as well as panel pillars. These pillars may be cut to increase extraction, with typical final overall extraction ratios of 50 to $65 \%$. The total panel width is typically approximately $175 \mathrm{~m}$ with barrier pillars left between panels.

Since 1994, a number of major panel or partial panel collapses have occurred with associated seismic events generated registering $2.5 \mathrm{M}_{\mathrm{L}}$ or greater (Figure 1). These events have typically occurred over several seconds of time, with resultant plug-type ground subsidence of approximately $1 \mathrm{~m}$. The seismic signatures of these events as monitored at remote sites have been analysed and fit a crack closure mechanism very well (e.g. 
Pechmann, et al., 1995). Prior to these collapses, significant closure in the underground panels was observed, as well as pillar sidewall spalling. Observations in the collapsed panels include excessive pillar floor punching and extreme floor heave, pillar sidewall spalling and extensive roof falls. However, in many instances the panels were not completely closed. Considerable difference of opinion has occurred as to whether the dominant mechanism of collapse was a rapid, progressive pillar failure, progressive pillar punching, possible arching and abutment shear failure of the overlying beds, particularly the Tower Sandstone, or a combination of these mechanisms.

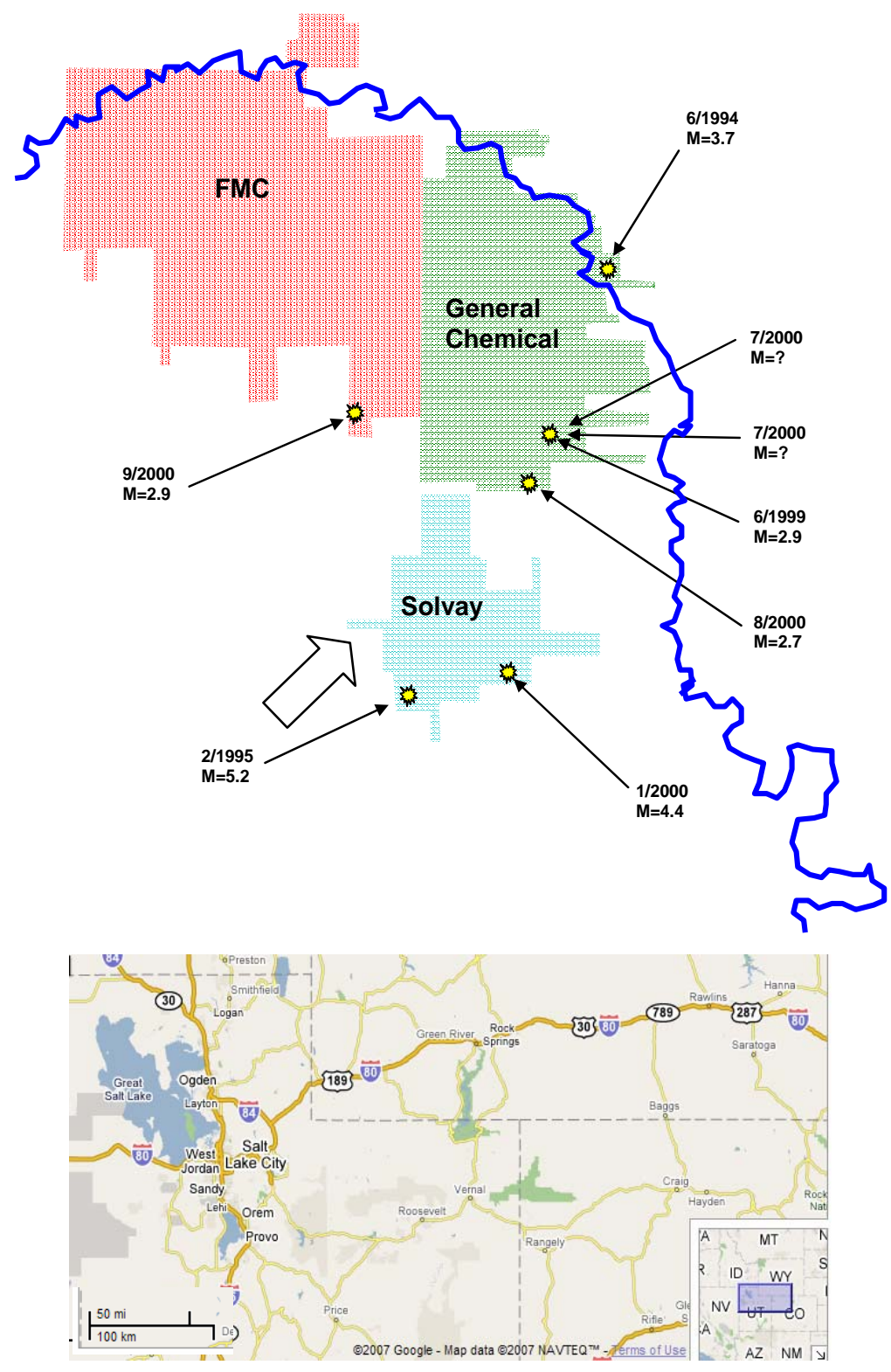

Figure 1 Location of site and seismic events in room and pillar or longwall operations in the Green River Basin, Wyoming trona mines through 2000

A methodology similar to the ground reaction curve procedure for tunnel support design was developed for analysis of the mechanism for the panel collapses, and for use in design. The procedure includes the following steps:

- Estimation of the stress-strain response of the pillar/floor system. Numerical modelling is used to simulate the loading and yield of the floor/pillar system and the development of a complete stressstrain curve. The model is calibrated against both observation and instrumentation of pillars during retreat mining. 
- The calibrated model is used to simulate the average stress-strain response of typical repeated groups of pillars (e.g. panel and chain pillars) for various extraction ratios and layouts. This provides a general panel stress-strain response.

- The pressure-closure response of the overburden rock is determined, taking into account the panel span and dimensions of inter-panel barrier pillars. The slope and form of this curve provides a measure of the stiffness and energy availability of the overlying strata.

- Superimposing the pillar/floor and surrounding strata pressure-strain (displacement) curves allows determination of overall panel stability and possible violence of the resulting deformation.

- Design variations in the panel layout (e.g. extraction ratio, pillar cutting procedures, panel span and barrier pillar dimensions) can easily be examined to determine the design basis for stable layouts.

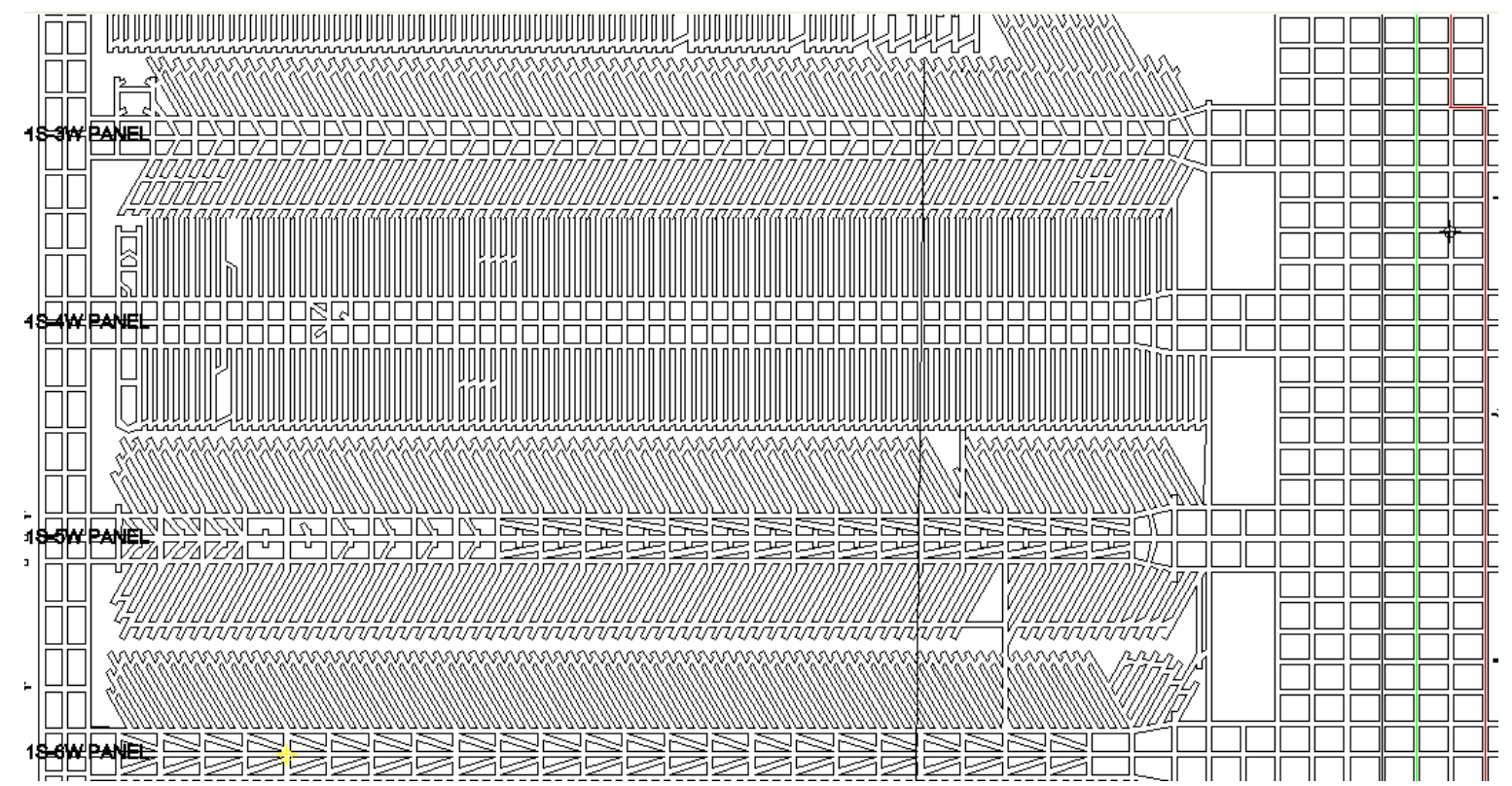

Figure 2 Typical panel arrangement showing approximately $175 \mathrm{~m}$ width panels

\section{Methodology}

\subsection{Geology and laboratory properties}

The general geology of the Green River Basin is shown in Figure 3. The primary trona bed (Bed 17) occurs at a depth of 450 to $490 \mathrm{~m}$ and is overlain by a series of shale and sandstone units. Of particular interest in this sequence are the relatively weak and thinly-bedded oil shale or shale floor that buckles and heaves readily during retreat mining, and the strong and thick $(83 \mathrm{~m})$ Tower Sandstone unit that is found approximately $90 \mathrm{~m}$ above the seam. The Tower (Figure 4) can be observed in shafts sunk through the overburden beds. It is a fine-grained, strong, but fractured sandstone with GSI estimated to be approximately 60. The interbedded mudstones, calcareous marlstones and shales are generally of lower strength and stiffness. The laboratory properties of the trona and immediate floor as well as the Tower are reviewed in Table 1.

\subsection{Observed pillar response and pillar model calibration}

Trona is a relatively strong and brittle evaporite which rests upon a weak, thinly-bedded shale floor. Field observations of pillar yield show that the $4 \mathrm{~m}$ wide panel pillars tend to punch into the floor with resultant buckling of the floor at the centerline of the rooms and shearing failure of the sidewalls of the pillar beginning at the floor line (Figure 5). Use of empirical classification schemes (e.g. Hoek, 1998) for estimation of the properties of trona or shale has a high degree of uncertainty. Therefore, the rock mass 
properties were estimated here by comparison of a numerical model to the observed pillar and floor failure behaviour as well as stress change instrumentation in the pillars and closure of the room. IRAD stress gauges and roof-to-floor convergence measurements were made at the Solvay Mine, 2 SW panel in more than 15 locations during the initial room advance and retreat mining operations. Figure 6 illustrates the general calibration process in which the UDEC discontinuum program was used to perform simulations of the mining of panel pillars on retreat. Here, the trona pillar is represented by a strain softening material model while the floor is represented by a thinly-bedded Mohr-Coulomb material in which the beds are modelled explicitly by horizontal fracture planes with friction angle of $30^{\circ}$. Analyses began with laboratory properties of the trona and shale, followed by parametric reduction in properties until the basic pillar sidewall spalling mechanism and floor punching response was reproduced. It was found that matching the observed floor punching and pillar sidewall spalling behaviour as well as the measured stress change at peak strength could only be achieved with a narrow range of shale properties - particularly the cohesion. Cohesion values of around 1.5 MPa were found to produce the observed response, whereas lower values tend to result in no pillar sidewall shearing and higher cohesion values limit punching and result in typical conjugate shear fracturing of the pillar, contrary to the floor-line sidewall shearing mechanism observed.

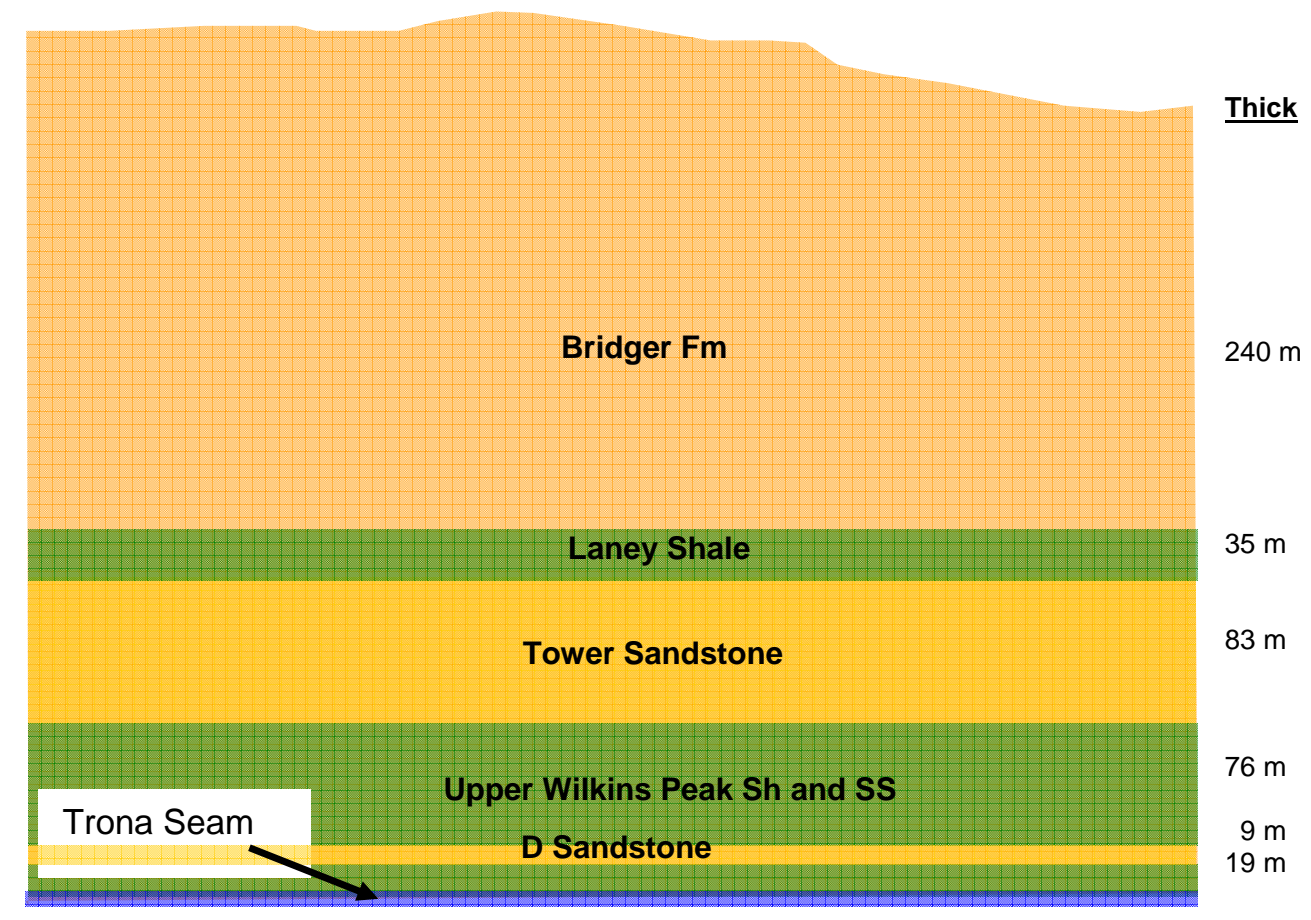

Figure 3 Overburden geology 


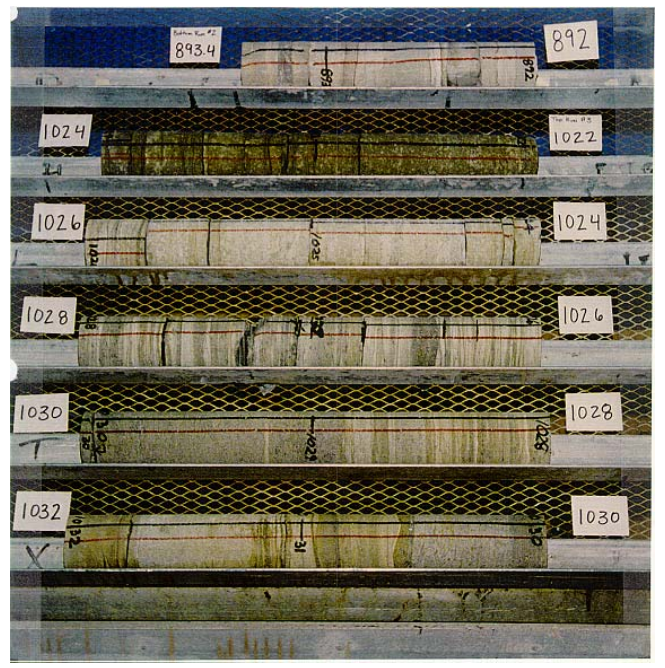

Figure 4 Photo of core from upper portion of Tower Sandstone, FMC Joint Oil/Gas and Trona Project hole (Fugro, 1997). Samples for mechanical testing taken from 314 to $317 \mathrm{~m}$ depth (1031 to $1039 \mathrm{ft}$ )

Table 1 Summary of laboratory rock properties Pariseau and Eitani1 (1976) and Terra Tek2 (1996)

\begin{tabular}{lccc}
\hline Rock Type & $\begin{array}{c}\text { Uniaxial } \\
\text { Compressive } \\
\text { Strength (MPa) }\end{array}$ & $\begin{array}{c}\text { Angle of Friction } \\
\text { (degrees) }\end{array}$ & $\begin{array}{c}\text { Young's Modulus } \\
\text { (GPa) }\end{array}$ \\
\hline Trona $^{1}$ & 46 & 36 & 28 \\
Oil Shale floor $^{1}$ & 33 & 17 & 5 \\
Tower & 115 & 42 & 21 \\
Sandstone $^{2}$ & & & \\
\hline
\end{tabular}

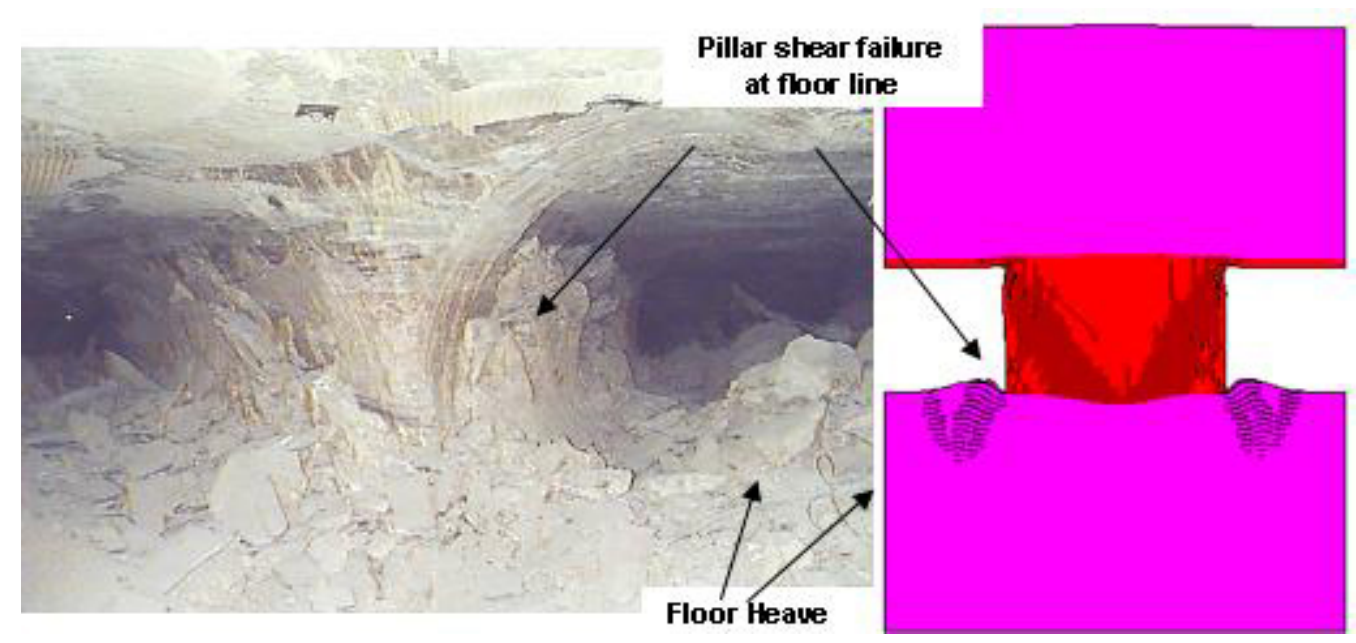

Figure 5 Typical panel rib pillar failure mechanism showing punching of pillar into weak oil shale floor and shear failure of pillar sidewalls that starts at the pillar floor as a result of punching (left). Comparison of the observed response is given to the numerical equivalent produced by the UDEC program (right). Here, the floor bed buckling and sidewall shear failure mechanism is reproduced for only a limited range of trona and shale floor properties 

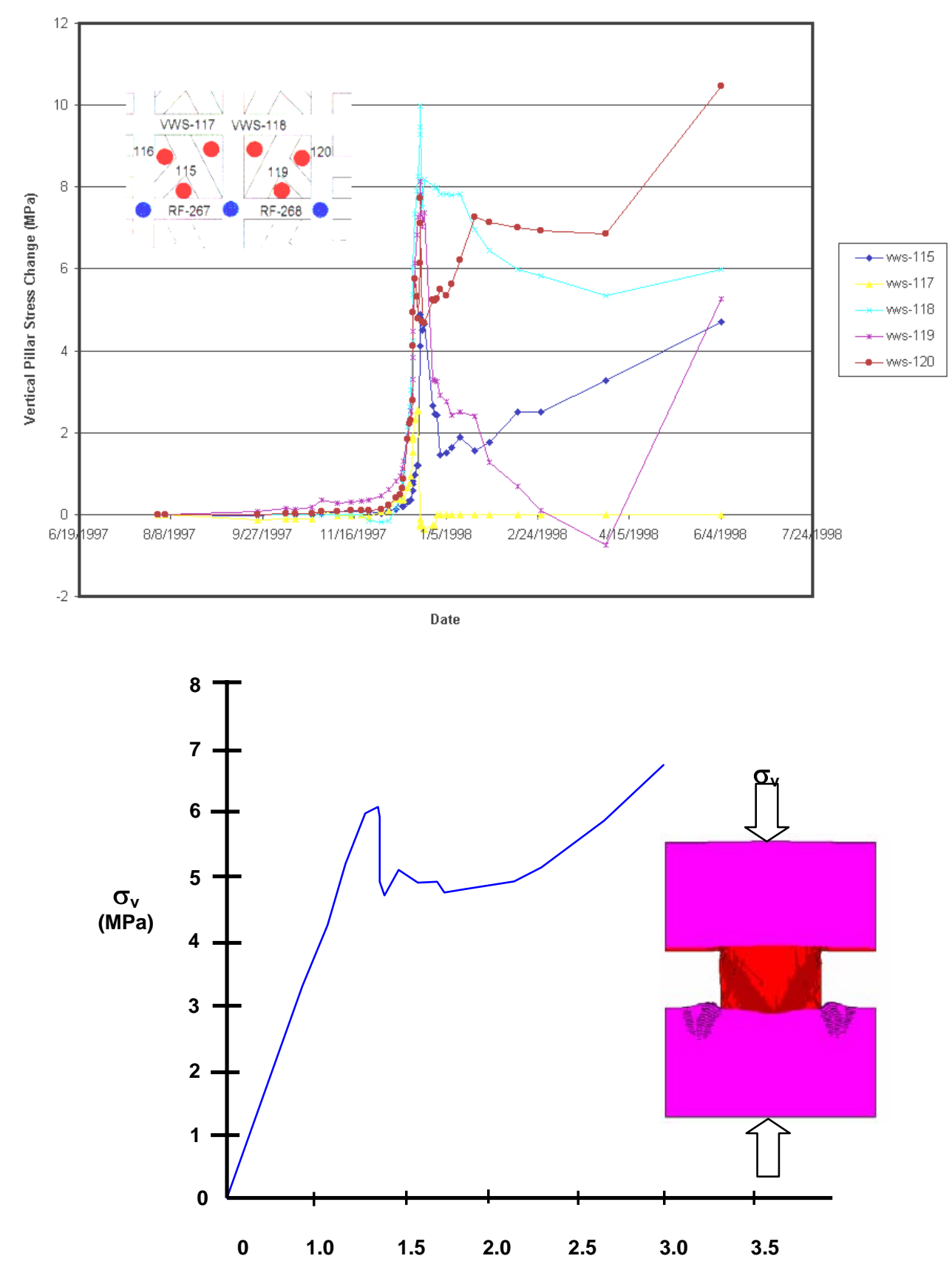

Figure 6 Typical stress change vs time plot measured in pillars that are created during retreat mining (top). Peak strength is 8 to 10 MPa over the tributary area load. Stress-strain curve shows brittle post-peak response followed by hardening with increased punching (top). Typical UDEC model calibration of stress change vs time (for quasi-statically loaded sample at constant strain rate) obtained by via parametric adjustment of the floor shale properties to allow punching (bottom)

Although the example in Figure 6 illustrates the calibration of rock mass properties for relatively simple shapes, pillar robbing can often result in complex pillar shapes as chain pillars are cut by bore miners. In these cases, three-dimensional numerical models are used for conducting simulated compression tests on pillars and estimating the average stress strain response for the cut pillars. Figure 7 illustrates a case in which the average stress-displacement (strain) response for various cutting schemes and extraction ratios has been developed using the FLAC3D model. Here, plan views through the centre of chain pillar cut schemes are shown which result in various extraction ratios. The failure state of the pillar is shown, with blue being the 
elastic core, red showing regions of shear failure and green shear and tensile failure. The derived average stress-displacement curves for each pillar scheme are shown.
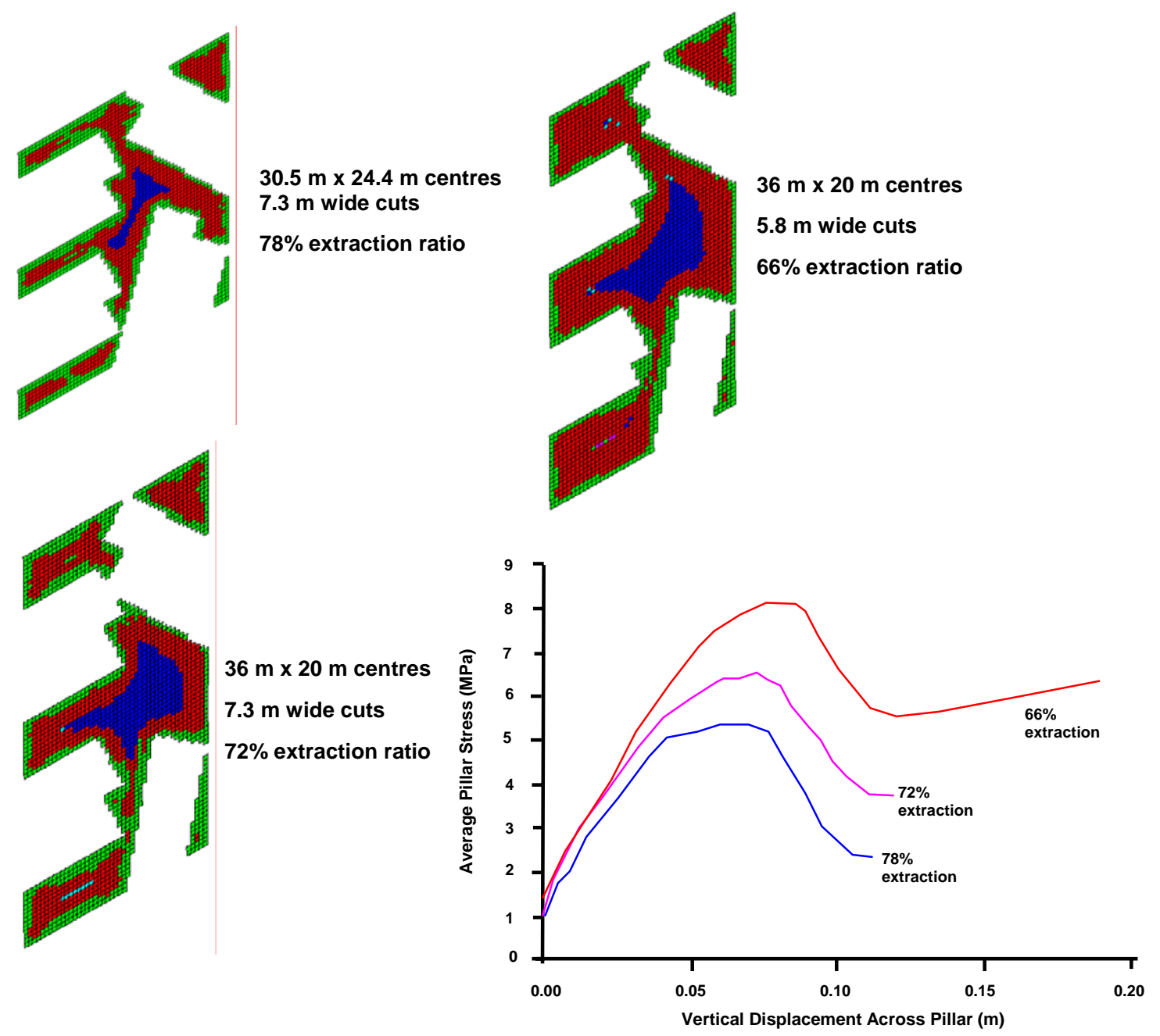

Figure 7 Plan view through centre of FLAC3D model of panel pillars cut by various retreat schemes. The plot shows the post-peak strength state of the pillars - blue is the elastic confined core, red are areas failed in shear and green are areas of tensile or shear failure. The resulting average pillar stress-displacement curves are shown for extraction ratios of 66 to $78 \%$

\subsection{The ground reaction response of the overburden}

The ground reaction or stress-displacement response of the overburden for a given panel span and barrier pillar layout is estimated numerically using either a two or three-dimensional model, depending on the shape of the panel. Most panel geometries in the Green River Basin mines are two-dimensional (see Figure 2). A cross-sectional model is constructed that includes the primary beds within the sequence (Figure 8).

A ground reaction curve for the overburden lithology is generated by progressive reduction in the average pressure applied to the roof. The ground reaction curve expresses the unloading stiffness of the overburden, and reflects the ability of the beds to form a stable pressure arch over the panel. Figure 8 illustrates schematically the formation of a stable pressure arch in which the panel span is narrow enough to provide a stable roof with no internal support. Of course, in most instances ground reaction curves will indicate an unstable roof. The average pressure at which complete closure occurs is a function of the depth of unstable roof that the pillars must support. Ground reaction curves that attain complete closure at an average pressure equal to the weight of the overburden to the ground surface indicate destruction of the pressure arch and development of full tributary area load. A curve that reaches full tributary area load at small roof deflection 
indicates the potential for violent shear failure of a strong, overlying bed that results in rapid development of full overburden load. The simple example in Figure 8 shows the hypothetical case of an isolated panel. In reality, the ground reaction curve will be a function of not just the overburden lithology, but the span of the panel and the dimensions of inter-panel barrier pillars. These issues can be examined numerically with no additional difficulty.
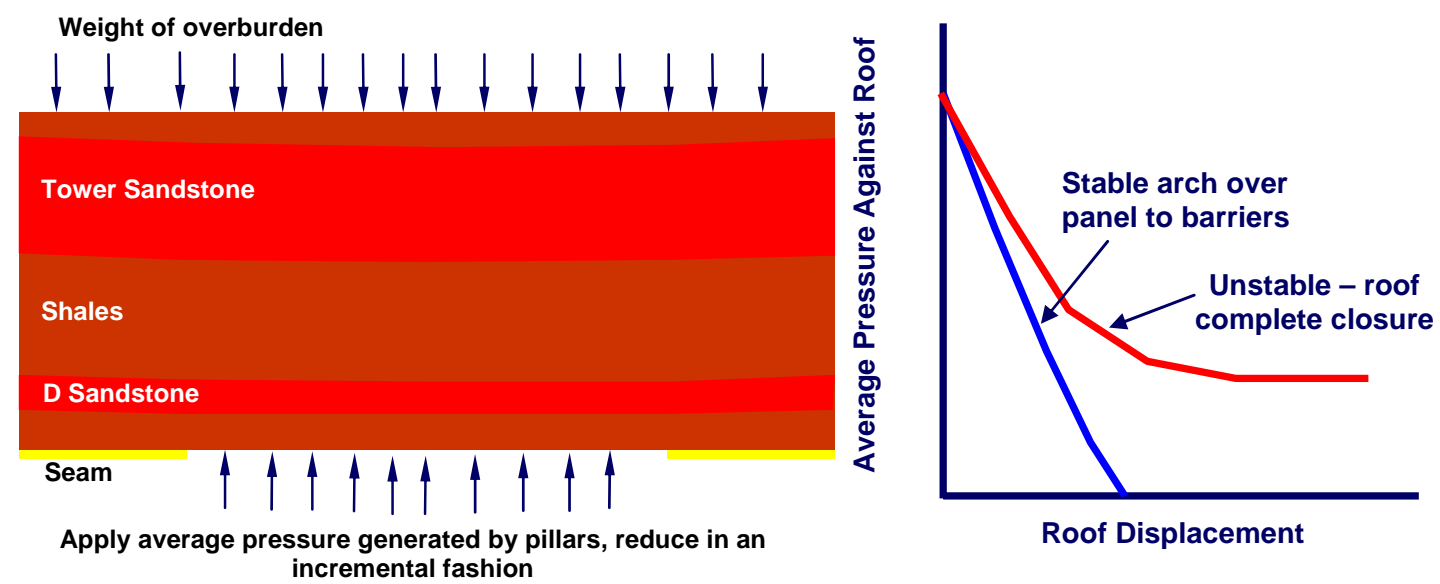

Figure 8 Schematic illustration of model to determine overburden ground reaction response. A simplified model of lithology with pillars replaced by a uniform pressure is developed. Incremental reduction of this pressure provides a ground reaction response

\subsection{Methodology for determination of panel stability}

Once the stress-displacement (strain) response of typical groups of pillars that represent various panel extraction schemes and ratios have been determined, they are superimposed on the ground reaction curves for various panel spans and barrier pillar arrangements. This is analogous to the use of the ground reaction curve for ground support design in which the force-displacement characteristic of the ground support is superimposed on the ground reaction curve for the tunnel to determine the equilibrium support load and deformation of the tunnel. Here, the intersection of the pillar stress-displacement and ground reaction characteristics indicate the equilibrium average pillar stress and closure of the seam. The analysis also indicates whether equilibrium can be achieved for a given extraction ratio, pillar and panel layout.

\section{Case example}

A case example of the collapse of a high extraction mining panel is given here. The mining consisted of development of a series of three panels, each approximately $175 \mathrm{~m}$ in width by $600 \mathrm{~m}$ in length, and separated by $21 \mathrm{~m}$ barrier pillars. The total width of the three panels and barriers was approximately $560 \mathrm{~m}$. The general panel designs are similar to that shown in Figure 2 - the panels are developed by three bore miner entries separated by chain pillars that are driven the length of the panel. The panel is developed in each direction perpendicular to the entries by creation of panel rib pillars on retreat. Initially, no additional pillar cutting was performed, resulting in an extraction ratio of approximately 50 to $55 \%$. The extraction ratio was slowly and progressively increased over the first two panels to a level in excess of $65 \%$ by the completion of the second panel. This was performed by cutting both the chain pillars and the panel pillars during the retreat. Pillar cutting resulted in yielding of both the chain pillar segments, as well as the panel rib pillars as shown in Figure 6. By the completion of the second panel, excessive sidewall pillar spalling as well as pillar punching and floor heave were observed. The panel pillar drifts exhibited room closures in excess of $1 \mathrm{~m}$ at this time. A third panel was initiated and the retreat reached approximately $495 \mathrm{~m}$ from the end of the previous panels when a major roof collapse accompanied by a large seismic event occurred. This collapse occurred over a period of a few seconds and resulted in approximately $1 \mathrm{~m}$ of surface subsidence directly over the high extraction portion of the panel.

The ground reaction curve methodology was applied in a back-analysis mode to examine this collapse. Figure 9 shows a cross sectional UDEC model of the panels and inter-panel barrier pillars. In this model, the 
D and Tower Sandstones are represented as strain softening materials characterised by a GSI of 60, deformation modulus of $21 \mathrm{GPa}$ and uniaxial compressive strength of $115 \mathrm{MPa}$. Average pillar stress-strain curves for the cut chain and panel rib pillars were determined for extraction ratios of 50 to $90 \%$. The resulting ground reaction curve for the three-panel layout superimposed on the average pillar stress strain curves is shown in Figure 9. The ground reaction curve indicates a very soft response that produces a dead weight load after roof displacements of a few tenths of a meter. The overburden failure mechanism is a shear failure of the Tower unit over the panel abutments. This snap-through failure results in a plug-type subsidence of approximately 1 to $1.5 \mathrm{~m}$ which closely resembles the observed near-vertical break angle over the collapsed panel (Figure 9). Figure 10 shows the pillar stress-strain response superimposed on the ground reaction curve for the overburden. Figure 10 illustrates that panel failure is indicated for those pillar stressstrain curves that do not intersect the ground reaction curves on the initial hardening portion of the curves (or, in particular, do not intersect it at all). It is seen that panel extraction ratios in excess of approximately $70 \%$, which reasonably agrees with the extraction ratio that was achieved when the collapse occurred, indicate collapse potential.
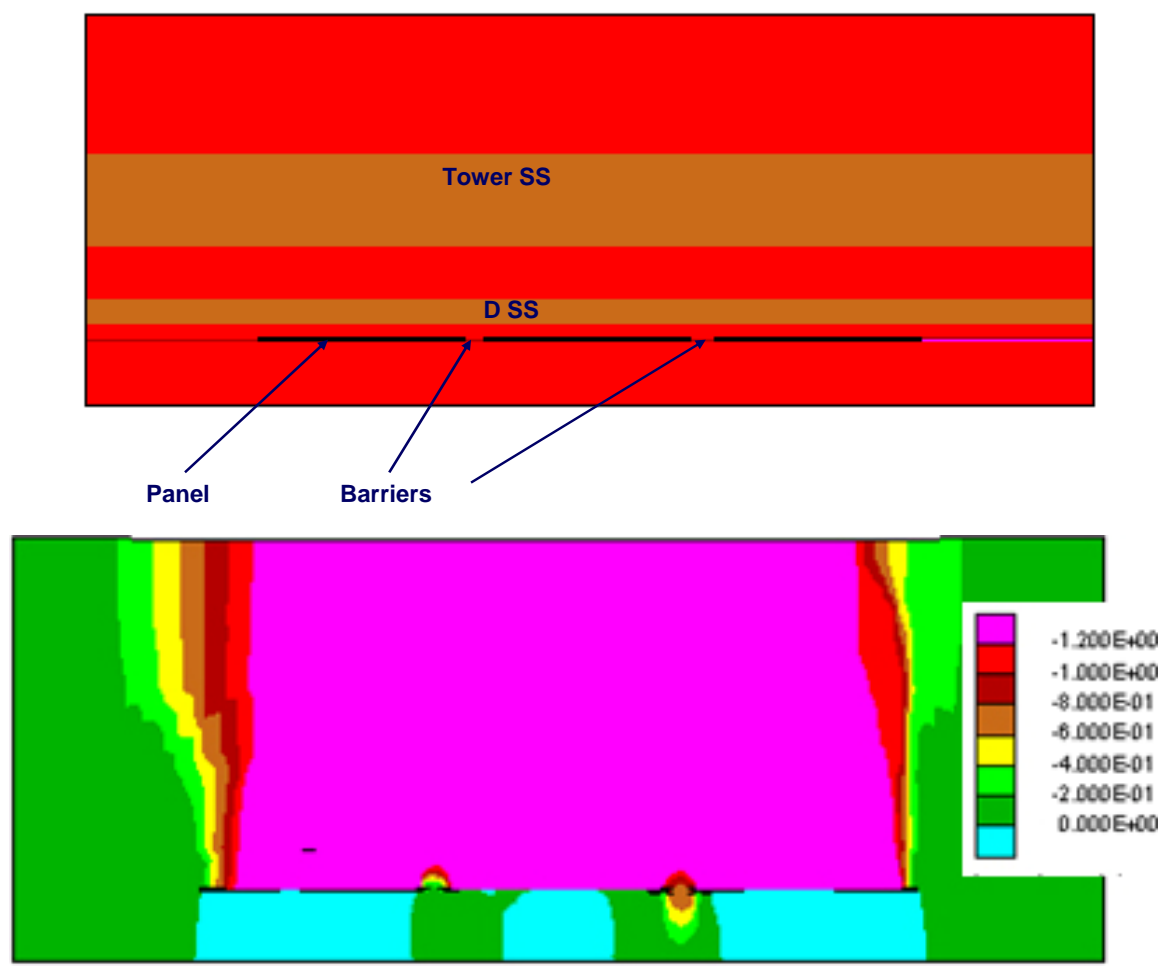

Figure 9 UDEC model of high extraction panels and overburden units (top) and vertical displacement contours after shear failure of the Tower Sandstone above the panel abutments (bottom). Note near-vertical break angle above abutments 


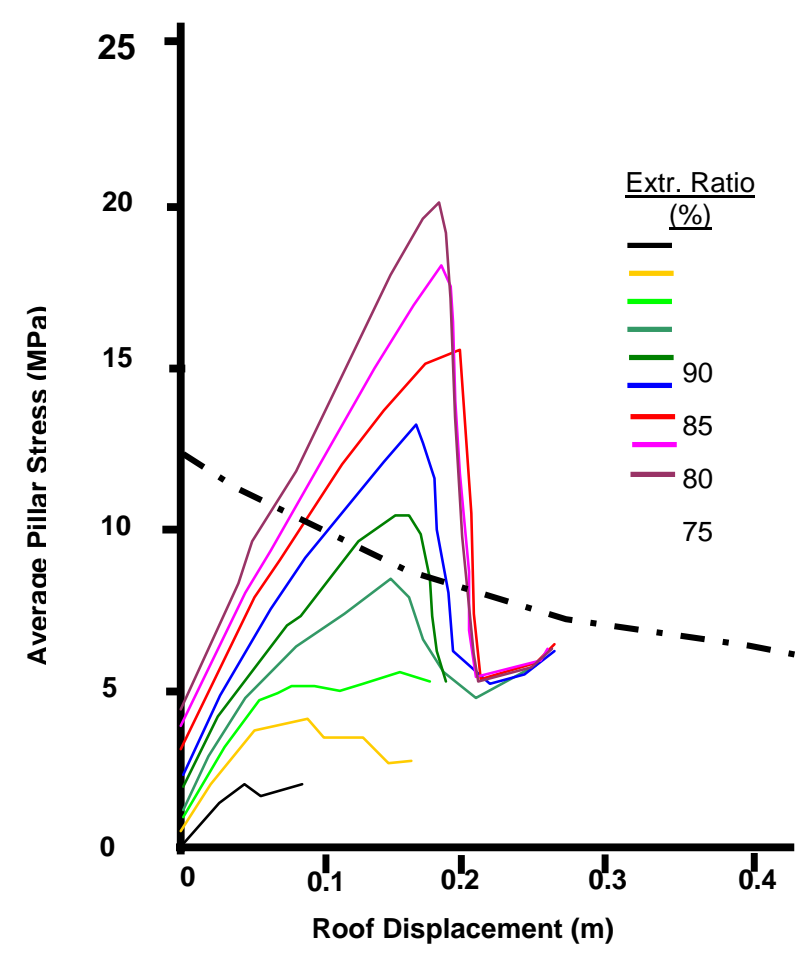

Figure 10 Average pillar stress-displacement (strain) plots for panel and cut chain pillars at extraction ratios of 50 to $90 \%$ superimposed with the ground reaction curve for the three panels and inter-panel barrier pillars

\section{Conclusions}

A methodology for examining the potential for collapse of room and pillar panels that accounts for the stressstrain response of the pillars and the stiffness of the overburden is described. The methodology involves development of average stress-strain curves for pillars based on numerical calibration to pillar failure observations and response measurements as well as ground reaction curves for the overburden, accounting for panel layout and barrier pillars. Equilibrium of the panel is determined by superimposing the ground reaction curve and the pillar stress-strain response. The potential violence of the collapse can be estimated from the shape of the ground reaction curve, and the position at which the pillar stress-strain curve intersects the ground reaction curve. Design studies are easily conducted using this technique. Pillar stress-strain curves can be generated for various extraction ratios as well as ground reaction curves for various panel and barrier pillar widths. Superimposing these curves can be used as a means of estimating the safety factor for various pillar extraction ratios. The analyses of the case study show that the collapse was the effect of high extraction ratio combined with a violent shear failure of a thick and strong overburden bed that was capable of a sudden application of full overburden loading on the entire panel geometry.

\section{References}

Fugro, Inc. (1997) Numerical analysis of trona-mining induced subsidence known sodium lease area, Green River, Wyoming. Prepared for Joint Oil/Gas \& Trona Industry Development Group, Green River, Wyoming, Rept. No. 0201-3069.

Hoek, E. (1998) Rock engineering course notes, University of Toronto, Ontario, Canada.

Pariseau, W.G. and Eitani, A. (1976) Laboratory rock properties: Alchem Mine. University of Utah, Rept. to Allied Chemical Corp., October.

Pechmann, J.C., Walter, W.R., Nava, S.J. and Arabasz, W.J. (1995) The February 3, 1995, M 5.1 Seismic event in the trona mining district of Southwestern Wyoming, 66 Seismol. Res. Letters 25.

Terra Tek, Inc. (1996) Physical and Mechanical Properties Characterization of OGT COEX 2, Sweetwater County, Wyoming. Prepared for the Joint Industry OGT Research Project, Rept. No. TR97-06. 